\title{
Early quantitative coronary angiography of saphenous vein grafts for coronary artery bypass grafting harvested by means of open versus endoscopic saphenectomy: A prospective randomized trial
}

\author{
L. P. Perrault, MD, PhD \\ H. Jeanmart, $M D^{a, b}$ \\ L. Bilodeau, MD \\ J. Lespérance, $M D^{\mathrm{e}}$ \\ J.-F. Tanguay, $M D^{d}$ \\ D. Bouchard, MD ${ }^{a, b}$ \\ P. Pagé, $M D^{a, b}$ \\ M. Carrier, MD ${ }^{a, b}$
}

Objective: Endoscopic saphenectomy is associated with a decreased incidence of wound complications without an increase in histologic trauma or endothelial dysfunction in published reports. Concern remains about the patency of saphenous vein grafts harvested endoscopically and the development of early intimal hyperplasia. The purpose of this study was to compare early quantitative coronary analysis of saphenous vein grafts used for coronary artery bypass grafting harvested with the open versus endoscopic techniques.

Methods: Forty patients undergoing primary coronary artery bypass grafting surgery with at least 1 saphenous vein graft were randomized preoperatively to open versus endoscopic saphenectomy with bipolar cauterization of side branches. Quantitative coronary angiography was performed a mean of 3 months (range, 1-9 months) after the operation.

Results: There was no statistically significant difference in the patency rates of internal thoracic artery grafts between the open and endoscopic groups and no statistically significant difference in the patency rates of saphenous vein grafts between both groups $(85.2 \%$ vs $84.4 \%, P=.991)$. Quantitative coronary angiography showed no difference in graft stenosis $(\geq 50 \%$ of the internal diameter of the graft) in the body of the saphenous vein grafts in the open versus endoscopic saphenectomy groups $(3.7 \%$ vs $0 \%, P=.280)$.

From the Research Center ${ }^{\mathrm{a}}$ and the Departments of Surgery, ${ }^{\mathrm{b}}$ Pharmacology, ${ }^{\mathrm{c}}$ Cardiology, ${ }^{\mathrm{d}}$ and Radiology, ${ }^{\mathrm{e}}$ Montreal Heart Institute and University of Montreal, Montreal, Quebec, Canada.

Received for publication June 26, 2003; revisions requested Oct 9,2003 ; accepted for publication Oct 23, 2003.

Address for reprints: L. P. Perrault, MD, $\mathrm{PhD}$, Research Center, Montreal Heart Institute, 5000 Belanger Street East, Montreal, Quebec H1T 1C8, Canada (E-mail: lpperrau@icm.umontreal.ca).

J Thorac Cardiovasc Surg 2004;127:1402-7

$0022-5223 / \$ 30.00$

Copyright (C) 2004 by The American Association for Thoracic Surgery

doi:10.1016/j.jtcvs.2003.10.040
Conclusion: Angiographic appearance and patency rates of saphenous vein grafts harvested with the endoscopic technique are similar to those of saphenous vein grafts harvested with the open technique. These results support the use of endoscopic saphenectomy because of the known lower incidence of wound and infectious complications and superior functional results.

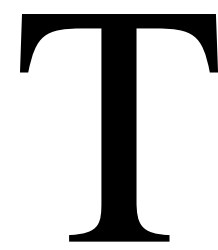

he internal saphenous vein used for coronary artery bypass grafting $(\mathrm{CABG})$ procedures is traditionally harvested by means of the open technique, and as a consequence, lower limb wound complications are an important source of morbidity after CABG, occurring in about $15 \%$ of cases. ${ }^{1}$ Complications such as hematoma, dehiscence, skin necrosis, or wound infection increase the length of stay ${ }^{2}$ and delay rehabilitation, ambulation, and exercise training. ${ }^{3}$ These complications are increased 
in cases of low ejection fraction, anemia, female sex, obesity, diabetes mellitus, and peripheral vascular disease. A recent study showed that the infection rate is independent of the closure technique used. ${ }^{4}$ In an attempt at decreasing local wound complications, improving delay for ambulation, and, to a lesser degree, obtaining a better cosmetic result, alternatives to classical techniques were developed. Bridging or tunneling techniques ${ }^{5}$ making use of a stripper through multiple incisions along the course of the saphenous vein allows shorter overall incision length but remains a blind procedure and technically difficult, although new devices allow harvesting of the vein under direct vision through sequential cutaneous incisions. ${ }^{6}$ Recent endoscopic techniques now allow total harvesting through a small incision by using videoscopic magnification, ${ }^{7,8}$ and this is the least invasive approach, reducing wound complications and postoperative pain, permitting early ambulation after surgical intervention, and improving overall patient satisfaction. ${ }^{9-11}$

Operative trauma can compromise the functional integrity of the saphenous vein ${ }^{3}$ and lead to poor vein quality, contributing to early occlusion and late fibrointimal hyperplasia. Better preservation of the endothelial architecture with the tunneling technique, as examined by means of light microscopy, has been reported. ${ }^{12}$ Functional studies assessing the vasoreactivity of the vein harvested endoscopically have shown no difference in endothelium-dependent relaxation between the open and endoscopic techniques, supporting preservation of the endothelial integrity of the graft. ${ }^{13-15}$ Angiographic studies documenting the patency of saphenous vein grafts harvested endoscopically are needed to confirm their preserved integrity.

The primary end points chosen for this study were the early patency and integrity of saphenous vein grafts harvested by using the open versus endoscopic techniques for $\mathrm{CABG}$, as assessed by means of quantitative coronary angiography (QCA). The secondary end points were comparison of operative mortality and postoperative complications, such as myocardial infarction, low cardiac output, and enzyme release, in the immediate postoperative period between the 2 groups.

\section{Patients and Methods \\ Study Population}

From December 2000 through May 2002, 40 patients undergoing primary $\mathrm{CABG}$ necessitating at least one saphenous vein graft at the Montreal Heart Institute were prospectively randomized into 2 groups, one undergoing open saphenectomy (open group) and the other undergoing endoscopic saphenectomy (endoscopy group). After patients had agreed to participate in the study and signed an inform consent form, they were randomized before the operation into blocks of 4 for equal sample size in the 2 groups. The study was approved and monitored by the Ethics Committee on Research and New Technology of the Research Center of the Montreal Heart Institute.

Exclusion criteria included the following: (1) history of saphenectomy or varicose saphenous vein precluding saphenectomy or impossibility to use the right lower limb for vein harvesting; (2) urgent operation for acute coronary occlusion at angioplasty or cardiogenic shock; and (3) emergency surgical procedures or reoperation for myocardial revascularization or valvular operations. No patients were excluded on the basis of body habitus, age, or quality of the vein or the distal coronary bed.

Of the 40 randomized patients, 5 patients in group 1 and 3 patients in group 2 refused the postoperative angiography for medical (sternal wound infection, renal insufficiency, and acute heart failure) or personal reasons and were excluded from the final analysis.

\section{Surgical Technique}

The operation was performed according to standard surgical techniques. Internal thoracic artery and saphenous vein grafts were used in all patients. The use of cardiopulmonary bypass or a beating-heart technique was left to the surgeon's discretion. Cardiopulmonary bypass was performed by using moderate hemodilution with a hematocrit level of between $20 \%$ and $25 \%$ and mild systemic hypothermia by permitting body temperature to drift down progressively to $33^{\circ} \mathrm{C}$, with the core temperature being thereafter maintained at that level with a heat exchanger until the aorta was unclamped. The proximal anastomoses to the aorta were performed with partial occlusion of the ascending aorta.

In the beating-heart group all surgeons used the same approach. The territory of the left descending artery (or a major diagonal branch) was revascularized first. The territory of the right coronary artery was then revascularized, and the lateral portion of the left ventricle was addressed at the end. All distal anastomoses were done with the use of a stabilizer. Proximal anastomoses were then performed with partial occlusion of the ascending aorta.

Open saphenectomy. In the open saphenectomy group dissection of the internal saphenous vein was done by using the standard technique with harvest of the vein at the ankle or thigh on the basis of the surgeon's preference and a continuous incision with tying off of branches with 3-0 silk or titanium clips and layered closure with absorbable suture material.

Endoscopic saphenectomy with $\mathrm{CO}_{2}$ insufflation. In the endoscopic saphenectomy group the system used was the Vasoview Uniport Endoscopic Vessel Harvesting System (Guidant, Markham, Ontario, Canada). A blunt-tip trocar was inserted in the incision, placing the conical tip on the anterior surface of the vein. A balloon was inflated with $30 \mathrm{~mL}$ of air to achieve the seal. Insufflation of $\mathrm{CO}_{2}$ was started to maintain a pressure of $15 \mathrm{~mm}$ $\mathrm{Hg}$ in the tunnel. Dissection of the internal saphenous vein was performed toward the groin by using the trocar on the anterior surface of the vein providing videoscopic magnification. Repeating the dissection along the posterior and the lateral aspect of the vein allowed us to expose all collaterals. Creation of a homogenous tunnel was then performed by means of insufflation of a $40-\mathrm{mL}$ balloon along the internal saphenous vein. By using bipolar scissors, collaterals were progressively cauterized and severed. The upper extremity of the vein was then clipped and sectioned through a 5-mm incision at the extremity of the tunnel. 
TABLE 1. Preoperative clinical and angiographic characteristics of the 2 groups of patients (mean \pm SD)

\begin{tabular}{lccc}
\hline & $\begin{array}{c}\text { Open } \\
(\mathbf{n = 1 5 )}\end{array}$ & $\begin{array}{c}\text { Endoscopic } \\
(\mathbf{n}=\mathbf{1 7})\end{array}$ & $\boldsymbol{P}$ value \\
\hline Age (y) & $64.0 \pm 7.9$ & $57.3 \pm 7.3$ & .54 \\
Women/men & $1 / 15$ & $2 / 17$ & .64 \\
Unstable angina & $12(60 \%)$ & $13(65 \%)$ & .81 \\
Hypertension & $15(75 \%)$ & $14(70 \%)$ & .054 \\
COPD & $2(10 \%)$ & $2(10 \%)$ & .89 \\
Diabetes & $11(55 \%)$ & $7(35 \%)$ & .071 \\
Three-vessel disease & $17(85 \%)$ & $16(80 \%)$ & .817 \\
Two-vessel disease & $3(15 \%)$ & $4(20 \%)$ & .817 \\
LV ejection fraction (\%) & $54.3 \pm 13.7$ & $60.0 \pm 11.5$ & .75
\end{tabular}

$C O P D$, Chronic pulmonary obstructive disease; $L V$, left ventricular.

Preparation of the vein and wound closure. In both groups the vein was then extracted, proximal dissection was completed under direct vision near the knee incision, and further dissection was performed toward the leg if necessary by using an endoscopic approach. All side branches were ligated with metallic clips, and the vein was prepared in the usual fashion after extraction in both groups. In the endoscopic group, at the end of the operation, the incisions in the thigh and leg were sutured with 2 subcutaneous stitches and Steri-strips on the skin after protamine administration. The leg was then wrapped with an elastic bandage for 24 hours. The postoperative anticoagulation regimen consisted of administration of $325 \mathrm{mg}$ of acetylsalicylic acid by mouth daily starting on day 1 or as soon as the patient was extubated.

Quantitative coronary angiography. Coronary angiography was performed 34 to 305 days after CABG (mean, 96 days) in the open group and 32 to 297 days after CABG in the endoscopic group (mean, 103 days) by using a standard technique through the femoral route. A dose of $0.3 \mathrm{mg}$ of nitroglycerin was injected selectively through each bypass graft. For each anastomotic site, the incidence that revealed the severest degree of stenosis was analyzed quantitatively with a computer-assisted method by using the Cardiovascular Measurement System (QCA-CMS, version 5.1, MEDIS medical imaging system, Leiden, The Netherlands). ${ }^{16} \mathrm{~A}$ frame was selected from the Dicom digital recording and displayed on a video monitor. An automatic edge-detection program determined the graft and coronary artery contours by assessing brightness along scan lines perpendicular to the center lines of the vessel. The image was calibrated on the basis of the known or measured size of the catheter, and the vessel diameters (in millimeters) were displayed for the length of the segment analyzed. The computer automatically calculated the minimum lumen diameter and the percentage diameter stenosis. The quantitative evaluation focused on 5 particular segments of interest: the proximal anastomoses; the proximal, mid, and distal thirds of the body of the graft; and the distal anastomoses. ${ }^{17}$ Both radiology technicians performing the QCA and the supervising senior radiologist were blinded to the type of vein-harvesting technique used.

\section{Data Analysis}

Analysis of continuous variables was performed with the Student $t$ test and the multivariate analysis of variance test. The $\chi^{2}$ test or the Fisher exact test were used for comparison of discontinuous data. The level of statistical significance was established at $95 \%$. Data are expressed as means and SDs. The degree of intraluminal stenosis was expressed in 5 categories: no stenosis, stenosis between $1 \%$ and less than $25 \%$, stenosis between $25 \%$ and less than $50 \%$, hemodynamically significant stenosis between $50 \%$ and $99 \%$, and occlusion (100\% of the luminal diameter).

\section{Results}

\section{Preoperative Profile of Patients}

The preoperative profiles of patients are presented in Table 1. The 2 groups of patients had similar preoperative characteristics. The majority of patients had 3-vessel coronary artery disease (85\% vs $80 \%, P=.817)$ and presented with unstable angina preoperatively $(60 \%$ vs $65 \%, P=.81)$. The mean ejection fraction was similar in both groups.

\section{Surgical Procedures}

In the open group (15 patients) $70 \%$ of operations were performed with the use of the cardiopulmonary bypass system, and 4 patients were operated on with beating-heart CABG techniques. The mean crossclamping and bypass times were $41.0 \pm 6.5$ minutes and $66.1 \pm 12.4$ minutes, respectively.

Forty-seven bypasses were constructed with 20 internal thoracic arteries and 27 vein grafts. The mean number of grafts per patient was 3.1 , with 1.8 vein grafts per patient.

In the endoscopic group (17 patients) $85 \%$ of operations were performed with the use of the cardiopulmonary bypass system, and 3 patients were operated on with off-pump coronary artery bypass (OPCAB) techniques. The mean crossclamping and bypass times were $33.4 \pm 5.4$ minutes and $62.2 \pm 7.3$ minutes, respectively (not significant vs the open group).

Fifty-three bypasses were constructed with 21 internal thoracic arteries and 32 vein grafts. The mean number of grafts per patient was 3.1, with 1.9 vein grafts per patient. There was no statistically significant difference in the number of total grafts and vein grafts between the 2 groups.

\section{Postoperative Morbidity and Mortality}

Data on postoperative morbidity and mortality are shown in Table 2. There were no deaths during the perioperative period in either group. No perioperative myocardial infarction, defined as peak troponin $\mathrm{T}$ values of greater than 10 $\mu \mathrm{g} / \mathrm{L}$ and creatine kinase $\mathrm{MB}$ values of greater than 50 IU/L, was recorded. Peak values of troponin T $(0.3 \pm 0.4$ $\mu \mathrm{g} / \mathrm{L}$ vs $0.3 \pm 0.5 \mu \mathrm{g} / \mathrm{L})$ and creatine kinase MB (21.9 \pm $18.9 \mathrm{IU} / \mathrm{L}$ vs $23.8 \pm 35.6 \mathrm{IU} / \mathrm{L})$ were similar in both groups. Only one stroke was reported in the open group. One leg wound infection was noted in the dissection group, and none were found in the endoscopic group. The lengths of intensive care unit and hospital stays were similar in both groups. 
TABLE 2. Comparison of postoperative morbidity and mortality between the 2 groups

\begin{tabular}{lccc}
\hline & $\begin{array}{c}\text { Open } \\
(\mathbf{n}=\mathbf{1 5})\end{array}$ & $\begin{array}{c}\text { Endoscopic } \\
(\mathbf{n}=\mathbf{1 7})\end{array}$ & $\boldsymbol{P}$ value \\
\hline Death (30 d) & 0 & 0 & 0 \\
Perioperative MI & 0 & 0 & 0 \\
Cerebrovascular accident & 1 & 0 & .295 \\
Reexploration for bleeding & 0 & 0 & 0 \\
Leg wound infection & 1 & 0 & .295 \\
ICU length of stay (d) & $3.2 \pm 1.7$ & $3.9 \pm 3.8$ & .873 \\
Hospital stay (d) & $9.5 \pm 4.2$ & $9.6 \pm 5.8$ & .989 \\
\hline
\end{tabular}

$M I$, Myocardial infarction; ICU, intensive care unit.

TABLE 3. Quantitative angiographic results of left internal thoracic artery graft to the anterior descending artery

\begin{tabular}{lccc}
\hline & Open & Endoscopic & $\boldsymbol{P}$ value \\
\hline No. of total grafts & 47 & 53 & .951 \\
No. of ITA grafts & 20 & 21 & .778 \\
Occluded grafts & $0(0 \%)$ & $1(4.8 \%)$ & .335 \\
No stenosis & $11(55 \%)$ & $12(57.1 \%)$ & .893 \\
$1 \%-<25 \%$ stenosis & $2(10 \%)$ & $3(14.3 \%)$ & .684 \\
$25 \%-<50 \%$ stenosis & $3(15 \%)$ & $2(9.5 \%)$ & .603 \\
$\geq 50 \%$ & $4(20 \%)$ & $3(14.3 \%)$ & .637 \\
\hline
\end{tabular}

ITA, Internal thoracic artery.

\section{Angiographic Results Determined by Means of QCA}

Internal thoracic artery grafts. Data on angiographic results with internal thoracic artery grafts are shown in Table 3. There was no statistically significant difference between the 2 groups in terms of graft occlusion $(0 \%$ vs $4.8 \%$ ), angiographic lesions greater than or equal to $50 \%$ of the internal diameter of the graft ( $20 \%$ vs $14.3 \%)$, lesions between $25 \%$ and less than $50 \%$ of the internal diameter of the graft (15\% vs $9.5 \%)$, and lesions between $1 \%$ and less than $25 \%$ of the internal diameter (10\% vs $14.3 \%)$.

Saphenous vein grafts. Data on saphenous vein grafts are shown in Table 4. Graft occlusion (14.8\% vs $15.6 \%)$ and grafts with lesions of $50 \%$ or more of the internal diameter (3.7\% vs $0 \%$ ) were similar in both groups. There was an increased number of vein grafts with angiographic lesions of less than $50 \%$ of the internal graft diameter in the endoscopic group $(40.7 \%$ vs $53.2 \%$ ), but that difference failed to reach statistical significance (Figure 1). The number of grafts occluded or with $50 \%$ or greater stenosis was not significantly different between the 2 groups ( 5 and 5 in the open and endoscopy groups, respectively, $P=.773$ ).

There was no saphenous vein graft occlusion in the 4 patients having OPCAB in the open group and a single saphenous vein occlusion in the endoscopic group $(P=$ .28).

Revision of the preoperative coronary angiography of patients with occluded vein grafts revealed no differences in
TABLE 4. Quantitative angiographic results of saphenous vein grafts

\begin{tabular}{lccc}
\hline & Open & Endoscopic & $\boldsymbol{P}$ value \\
\hline No. of SVGs & 27 & 32 & .930 \\
Occluded grafts & $4(14.8 \%)$ & $59(15.6 \%)$ & .933 \\
No stenosis & $11(40.7 \%)$ & $10(31.2 \%)$ & .457 \\
$1 \%-<25 \%$ stenosis & $2(7.4 \%)$ & $6(18.8 \%)$ & .212 \\
$25 \%-<50 \%$ stenosis & $9(33.3 \%)$ & $11(34.4 \%)$ & .934 \\
$\geq 50 \%$ & $1(3.7 \%)$ & $0(0 \%)$ & .280
\end{tabular}

SVG, Saphenous vein graft.

the quality of the distal coronary bed between the 2 groups. All native vessels had a high-grade stenosis of more than $70 \%$ (except one patient in each group), and the majority were good target vessels for bypass grafting. There were more occluded vein grafts in the posterior descending artery territory in group 1, but there was more occlusion in the anterolateral territory in group 2 .

Further analysis of the angiographic lesions of less than $50 \%$ of the internal diameter of the graft revealed that there was no statistically significant difference in terms of diameter, area, and length of the lesions between the 2 groups.

\section{Discussion}

The major findings of this study are as follows. First, endoscopic harvesting of the internal saphenous vein has a similar rate of graft patency in the early postoperative period when compared with that of traditional open saphenectomy. To our knowledge, this is the first randomized angiographic study comparing these 2 techniques of saphenectomy.

CABG remains the most common procedure in adult cardiac surgery. The internal thoracic artery and the internal saphenous vein are the conduits of choice in many centers around the world. Different approaches have been investigated in an attempt to reduce the rate of wound complications associated with harvesting of the saphenous vein, including wound infection or dehiscence, skin necrosis, and 


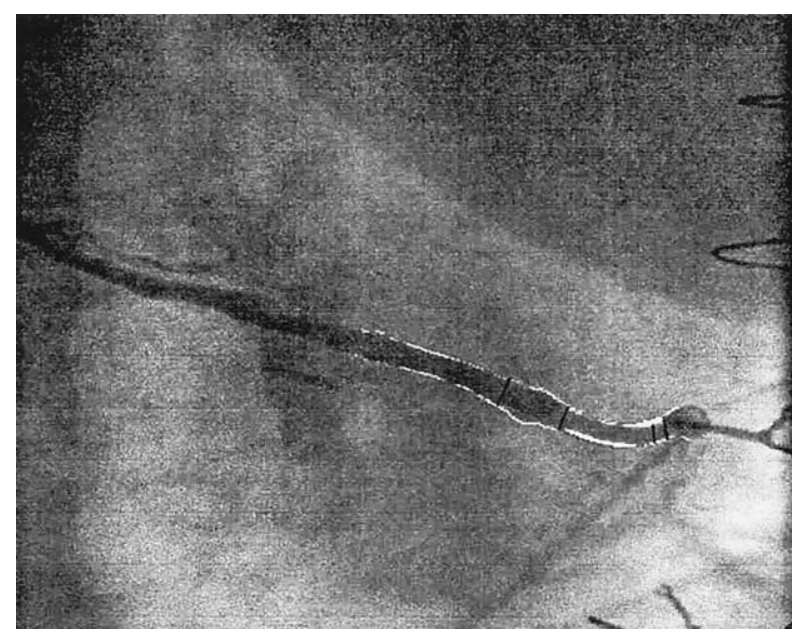

Figure 1. Quantitative angiographic results of saphenous vein grafting. Example of a lesion less than $\mathbf{5 0 \%}$ of the internal diameter of the vein graft (38\% stenosis in this case), as determined by using the OCA method.

leg swelling, which decrease patient postoperative mobility and satisfaction. Moreover, the poorer cosmetic result remains an important issue for many patients. In recent years, the tunneling technique (bridging technique) and endoscopic saphenectomy have become 2 of the most popular techniques used to decrease wound complications.

The bridging or tunneling technique ${ }^{5}$ with a stripper through multiple incisions along the course of the saphenous vein allows shorter overall incision length but remains a blind procedure and technically difficult. Endoscopic techniques have been developed to allow harvesting through a small incision by using videoscopic magnification, ${ }^{7,8}$ with or without gas insufflation. These techniques are associated with a decrease in wound complications and postoperative pain and an increase in patient satisfaction and ambulation after the operation. ${ }^{9-11}$ Furthermore, a recent study by Carpino and colleagues ${ }^{18}$ demonstrated a decrease in the infection rate in a group of patients at high risk for wound infection by using endoscopic saphenectomy compared with open saphenectomy. These interesting clinical results support a more liberal use of endoscopic saphenectomy for all patients, but the integrity and long-term patency of saphenous vein grafts harvested with the endoscopic method remains to be investigated to ensure the long-term security of this approach.

The reported rate of saphenous vein graft patency is variable according to the time period of the observation. A $10 \%$ to $15 \%$ rate of closure is seen in the first month after the operation, followed by a another 5\% to $10 \%$ attrition rate in the next 11 months caused by anastomotic errors, injury to the conduit, low flow, and disease of the target coronary artery. ${ }^{19}$ Another factor affecting the graft failure rate is the development of fibrous intimal hyperplasia in the vein graft. This process is uniformly distributed throughout the graft but might be focally or segmentally prominent in the early stages and is usually complete by 12 months. The cells associated with fibrous intimal hyperplasia have ultrastructural features of smooth muscle cells with a matrix of acid mucopolysaccharide. ${ }^{20}$ Scarring and thick collagen bundles develop in the media as smooth muscle cells are replaced. ${ }^{21}$ Recent studies suggest a patency rate of saphenous vein graft between $70 \%$ and $85 \%$ at 30 months, which is in contrast to the internal thoracic artery patency, which approximates $100 \% .{ }^{22}$ Modifications in graft harvesting and preservation, the postoperative use of antiplatelet agents, and control of dyslipidemia improved the patency rate. The use of a no-touch technique with harvesting of the saphenous vein with surrounding tissue, as reported by Souza and associates, ${ }^{23}$ improved vein graft patency at 18 months when compared with the conventional technique $(95.4 \%$ vs $88.9 \%$, respectively).

Studies investigating functional consequences and structural integrity have shown that regardless of the harvest technique used (open vs endoscopy), endothelial, elastic lamina, and smooth muscle cell continuity, as well as medial and adventitial connective tissue uniformity, were not statistically different. ${ }^{24,25}$ Black and coworkers ${ }^{26}$ studied the influence of saphenous vein graft harvesting techniques on the endothelial function and found that there was no difference in smooth muscle contractions or vasorelaxation in response to both endothelium-dependent and endothelium-independent agonists between minimally invasive saphenous vein harvesting and open saphenectomy.

In the present study the occlusion rate of saphenous vein grafts in the open saphenectomy group was $14.8 \%$, and the occlusion rate was $15.6 \%$ in the endoscopic group, a nonstatistically significant difference. There was no statistically significant difference in the number of angiographic significant lesions (lesion $\geq 50 \%$ of the internal diameter of the graft) in the body of grafts in both groups. There was a tendency toward an increase in the number of mild angiographic lesions (lesion $<50 \%$ of the internal diameter of the graft) in the endoscopic group versus the open group, but this was not statistically significant. The clinical significance of these mild angiographic lesions remains elusive. There was no difference in the occlusion rate or rate of greater than $50 \%$ lesions in the OPCAB between the 2 groups. Progressive intimal hyperplasia at the site of branch coagulation, clipping, or both could possibly explain these results. A progressive scar formation with retraction could narrow the luminal diameter of the graft and create a zone of turbulence that could favor the appearance of intimal hyperplasia. Progressive smooth muscle cell migration and proliferation could theoretically occur, leading to progressive narrowing of the luminal diameter at these particular 
sites of the graft. A longer period of observation will be needed to evaluate the evolution of these lesions and their effect on graft failure.

Despite its small sample size, the results of this study support the safety of endoscopic saphenectomy for saphenous vein grafts when compared with the gold standard of open saphenectomy, as assessed by means of early QCA analysis. Despite the fact that early angiographic assessment cannot exclude the development of late graft intimal hyperplasia, it does document the absence of gross vein trauma leading to occlusion and early stenosis. Moreover, the study population included mostly young male patients and cannot be readily extrapolated to patients with technical difficulties, such as obese elderly women with friable veins. However, no patients randomized were excluded on the basis of poor vein quality. These results support the standard use of endoscopic saphenectomy for CABG surgery in the population studied because the previously reported wound complication rate is lower and patient satisfaction is higher with similar short-term angiographic results. A longer observation period and repeat angiographic studies documenting the long-term safety of this approach would be ideal, although increasingly difficult logistically in the current era.

We thank all the staff of the Radiology Department of the Montreal Heart Institute for their work on this project, especially the QCA core lab technicians (France Bélanger, Marie-Josée Dussault, and Colette Desjardins) and Dr Lespérance for their expertise in the QCA evaluation.

\section{References}

1. Lavee J, Schneiderman J, Yorav S, Shewach-Millet M, Adar R. Complications of saphenous vein harvesting following coronary artery bypass surgery. J Cardiovasc Surg. 1989;30:989-91.

2. DeLaria GA, Hunter JA, Goldin MD, Serry C, Javid H, Najafi H. Leg wound complications associated with coronary revascularization. J Thorac Cardiovasc Surg. 1981;81:403-7.

3. Bourassa MG, Campeau L, Lesperance J. Changes in grafts and in coronary arteries after coronary bypass surgery. Cardiovasc Clin. 1991;21:83-100.

4. Mullen JC, Bentley MJ, Mong K, et al. Reduction of leg wound infections following coronary artery bypass surgery. Can J Cardiol. 1999;15:65-8.

5. Meldrum-Hanna W, Ross D, Johnson D, Deal C. An improved technique for long saphenous vein harvesting for coronary revascularization. Ann Thorac Surg. 1986;42:90-2.

6. Tevaearai HT, Mueller XM, von Segesser LK. Minimally invasive harvest of the saphenous vein for coronary artery bypass grafting. Ann Thorac Surg. 1997;63(suppl):S119-21.

7. Davis Z, Jacobs HK, Zhang M, Thomas C, Castellanos Y. Endoscopic vein harvest for coronary artery bypass grafting: technique and outcomes. J Thorac Cardiovasc Surg. 1998;116:228-35.
8. Morris RJ, Butler MT, Samuels LE. Minimally invasive saphenous vein harvesting. Ann Thorac Surg. 1998;66:1026-8.

9. Allen KB, Heinmansohn DA, Robison RJ, et al. Risk factors for leg wound complications following endoscopic versus traditional saphenous vein harvesting. Heart Surg Forum. 2000;3:325-30.

10. Coppoolse R, Rees W, Krech R, Hufnagel M, Seufert K, Warnecke H. Routine minimal invasive vein harvesting reduces postoperative morbidity in cardiac bypass procedures. Clinical report of 1400 patients. Eur J Cardiothorac Surg. 1999;16(suppl 2):S61-6.

11. Schurr UP, Lachat ML, Reuthebuch O, et al. Endoscopic saphenous vein harvesting for $\mathrm{CABG}-\mathrm{a}$ randomized, prospective trial. J Thorac Cardiovasc Surg. 2002;50:160-3.

12. Tran HM, Paterson HS, Meldrum-Hanna W, Chard RB. Tunnelling versus open harvest technique in obtaining venous conduits for coronary bypass surgery. Eur J Cardiothorac Surg. 1998;14:602-6.

13. Cable DG, Dearani JA, Pfeifer EA, Daly RC, Schaff HV. Minimally invasive saphenous vein harvesting: endothelial integrity and early clinical results. Ann Thorac Surg. 1998;66:139-43.

14. Griffith GL, Allen KB, Waller BF, et al. Histologic comparison of endoscopic versus traditionally harvested saphenous vein. Ann Thorac Surg. 2000;69:520-3.

15. Fabricius A. Endothelial integrity of saphenous veins harvested by two different minimally invasive techniques [abstract]. Heart Surg Forum. 1999;2(Suppl):S.61.

16. Reiber JHC, van der Zwet PMJ, von Land CD, et al. Quantitative coronary arteriography: equipment and technical requirements. In: Reiber JHC, Serruys PW, editors. Advances in quantitative coronary arteriography. Dordrecht, the Netherlands: Kluwer Academic Publishers; 1993. p. 75-111.

17. Poirier NC, Carrier M, Lespérance J, et al. Quantitative angiographic assessment of coronary anastomoses performed without cardiopulmonary bypass. J Thorac Cardiovasc Surg. 1999;117:292-7.

18. Carpino PA, Khabbaz KR, Bojar RM, et al. Clinical benefits of endoscopic vein harvesting in patients with risk factors for saphenectomy wound infections undergoing coronary artery bypass grafting. J Thorac Cardiovasc Surg. 2000;119:69-75.

19. Grondin CM, Lesperance J, Bourassa MG, Pasternac A, Campeau L, Grondin P. Serial angiographic evaluation in 60 consecutive patients with aortocoronary artery vein grafts 2 weeks, 1 year and 3 years after operation. J Thorac Cardiovasc Surg. 1974;67:1-6.

20. Lawrie GM, Lie JT, Morris GG Jr, Beazley HL. Vein graft patency and intimal proliferation after aortocoronary bypass: early and long-term angiopathologic correlations. Am J Cardiol. 1976;38:856-62.

21. Grondin CM, Campeau L, Lesperance J. Atherosclerotic changes in coronary vein grafts six years after operation: angiographic aspect in 110 patients. J Thorac Cardiovasc Surg. 1979;77:24-31.

22. Moran SV, Baeza R, Guera E, et al. Predictors of radial artery patency for coronary bypass operations. Ann Thorac Surg. 2001;72:1552-6.

23. Souza DS, Dashwood MR, Tsui JC, et al. Improved patency in vein grafts harvested with surrounding tissue: results of randomized study using three harvesting techniques. Ann Thorac Surg. 2002;73:1189-95.

24. Alrawi SJ, Balaya F, Raju R, Cunningham JN Jr, Acinapura AJ. A comparative study of endothelial cell injury during and endoscopic saphenectomy: an electron microscopic evaluation. Heart Surg Forum. 2001;4:120-7.

25. Griffith GL, Allen KB, Waller BF, et al. Endoscopic and traditional saphenous vein harvest: an histological comparison. Heart Surg Forum. 1999;2(Suppl):S.64.

26. Black EA, Guzik TJ, West NE, et al. Minimally invasive saphenous vein harvesting: effects on endothelial and smooth muscle function. Ann Thorac Surg. 2001;71:1503-7. 